\title{
A Basic Effect of Cloud Radiative Effects on Tropical Sea Surface Temperature Variability
}

\author{
YING LI AND DAVID W. J. THOMPSON \\ Department of Atmospheric Science, Colorado State University, Fort Collins, Colorado \\ DIRK OLONSCHECK \\ Max Planck Institute for Meteorology, Hamburg, Germany
}

(Manuscript received 20 April 2019, in final form 17 December 2020)

\begin{abstract}
Cloud radiative effects (CREs) are known to play a central role in governing the long-term mean distribution of sea surface temperatures (SSTs). Very recent work suggests that CREs may also play a role in governing the variability of SSTs in the context of El Niño-Southern Oscillation. Here, the authors exploit numerical simulations in the Max Planck Institute Earth System Model with two different representations of CREs to demonstrate that coupling between CREs and the atmospheric circulation has a much more general and widespread effect on tropical climate than that indicated in previous work. The results reveal that coupling between CREs and the atmospheric circulation leads to robust increases in SST variability on time scales longer than a month throughout the tropical oceans. Remarkably, cloud-circulation coupling leads to more than a doubling of the amplitude of decadal-scale variability in tropical-mean SSTs. It is argued that the increases in tropical SST variance derive primarily from the coupling between SSTs and shortwave CREs: Coupling increases the memory in shortwave CREs on hourly and daily time scales and thus reddens the spectrum of shortwave CREs and increases their variance on time scales spanning weeks to decades. Coupling between SSTs and CREs does not noticeably affect the variance of SSTs in the extratropics, where the effects from variability in CREs on the surface energy budget are much smaller than the effects from the turbulent heat fluxes. The results indicate a basic but critical role of CREs in climate variability throughout the tropics.
\end{abstract}

\section{Introduction}

An increasing body of literature suggests that cloud radiative effects (CREs) play a key role in governing not only the mean atmospheric circulation and its response to global warming but also its variability across a range of spatial and temporal scales. The advent of various remotely sensed cloud products such as those derived from the CloudSat-CALIPSO (Stephens et al. 2002) satellites has provided unprecedented insight into the vertical structure of clouds in the long-term mean (Zhang et al. 2007; Su et al. 2011; Su and Jiang 2013; Li et al. 2014b) and into the signatures of large-scale climate variability in various cloud properties in both the extratropics ( $\mathrm{Li}$ et al. 2014a; Wall and Hartmann 2015; Li and Thompson 2016) and tropics (Eguchi and Shiotani 2004; Masunaga et al. 2008; Chen and Genio

\footnotetext{
Corresponding author: David Thompson, david.thompson@colostate. edu
}

2009; Tromeur and Rossow 2010; Jiang et al. 2011; Riley et al. 2011; Ma and Kuang 2011; Yuan and Houze 2013; Crueger and Stevens 2015). Numerical experiments run with varying representations of CREs have revealed the central role of clouds in simulations of the mean tropospheric and stratospheric circulations (Fermepin and Bony 2014; Li et al. 2015, 2017; Harrop and Hartmann 2016; Watt-Meyer and Frierson 2017), in the simulated atmospheric circulation response to climate change (Ceppi et al. 2012, 2014; Ceppi and Hartmann 2015; Voigt and Shaw 2015, 2016; Ceppi and Hartmann 2016; Fläschner et al. 2018; Li et al. 2019; Voigt et al. 2019; Albern et al. 2019), and in the amplitude of climate variability in the context of the MJO (Lee et al. 2001; Crueger and Stevens 2015) and the spectrum of tropical waves (Zurovac-Jevtić et al. 2006; Lin et al. 2007).

Two recent studies have argued that cloud radiative feedbacks also play an important role in governing the amplitude and periodicity of El Niño-Southern Oscillation (ENSO) (Rädel et al. 2016; Middlemas et al. 2019). The 
studies both exploit "locked clouds" experiments, but they were run on different numerical models and used slightly different experimental frameworks. In both studies, the effects of CREs on the circulation are estimated by comparing output from 1) a control simulation where CREs are coupled to the atmospheric circulation and 2) a locked-clouds simulation where the cloudrelated properties input into the model radiation code are decoupled from the atmospheric circulation. In the case of Middlemas et al. (2019), the CREs in the locked simulation were determined by repeating values of the CREs derived from a single sample year from the control simulation. As such, the CREs prescribed in the locked run have a similar diurnal and seasonal cycle to those found in the control run, but no interannual variability. In the case of Rädel et al. (2016), the CREs in the locked simulation were determined by randomizing the year assigned to each radiation call time step in the control output. The two studies yield slightly different results: Rädel et al. (2016) found that ENSO variability is enhanced across all time scales when CREs are coupled to the atmospheric circulation due to positive longwave cloud radiative feedbacks, whereas Middlemas et al. (2019) found ENSO variability is only enhanced on time scales shorter than 6 years, but reduced on time scales longer than that due to negative shortwave cloud radiative feedbacks.

One possible reason for the different responses in the two simulations is differences in the model treatment of shortwave and longwave feedbacks (Lloyd et al. 2011, 2012; Bellenger et al. 2014). For example, as discussed in Middlemas et al. (2019), the ENSO response to changes in cloud properties depends on the amplitudes in the CESM1.2 and MPI models of 1) the model shortwave and longwave cloud radiative feedbacks relative to 2) the other model feedbacks that are essential for the simulated ENSO variability.

Another possible reason is differences in the locking methodologies, in particular the effects of the locking methodologies on the autocorrelation of the prescribed cloud fields. The locked-cloud fields in Middlemas et al. (2019) consist of annually repeating values drawn a single year from the control. The cloud fields in the control and locked simulations thus have roughly the same autocorrelation. In contrast, the locked-cloud fields in Rädel et al. (2016) are randomized such that they have no memory on time scales longer than $2 \mathrm{~h}$.

Here we hypothesize that removing the autocorrelation of the prescribed cloud fields in the scrambling methodology is important for fully identifying the effects of cloud-circulation coupling on the atmosphere. Specifically, we hypothesize that 1) cloud-circulation coupling imparts memory to CREs that would not exist in the absence of forcing by the large-scale flow, 2) the memory in CREs acts to increase the persistence of shortwave radiative fluxes at the surface, and 3) the reddening of the shortwave fluxes leads to increased low-frequency variance in the SST field. It is suggested that a basic effect of coupling between clouds and the atmospheric circulation is thus to redden the spectrum of shortwave CREs, hence reducing their variance on daily and shorter time scales but increasing their variance on lower-frequency time scales. The increased variance of shortwave CREs on low-frequency time scales, in turn, leads to notable increases in the SST variance over the tropics, where surface temperature variability is dominated by the shortwave radiative flux. Importantly, the coupling between CREs and the atmospheric circulation enhances the month-to-month variability of SSTs by a factor of 2-3 not only in the tropical Pacific, but throughout the tropical oceans. The coupling has little effect on SST variance over the extratropics, where surface temperature variability is dominated by the turbulent heat fluxes.

\section{Locked-clouds simulations}

As in Rädel et al. (2016) and Middlemas et al. (2019), the influence of CREs on the circulation are assessed by comparing output from 1) a control simulation where CREs are coupled to the atmospheric circulation and 2) a locked-clouds simulation where the CREs are prescribed and thus decoupled from the circulation.

The simulations were run on the latest version of the Max Planck Institute Earth System Model at low resolution (MPI-ESM1.2-LR), and with preindustrial forcing [note that the experiments in Rädel et al. (2016) were run on an earlier version of the model: the MPIESM1.0-LR]. The model has T63 $(\sim 200 \mathrm{~km})$ horizontal resolution and 47 vertical layers in the atmosphere component (ECHAM6.3), and nominal $1.5^{\circ}$ horizontal resolution and 40 vertical layers in the ocean component (MPIOM 1.6.3). The MPI-ESM1.2-LR is the baseline version used in phase 6 of the Coupled Model Intercomparison Project (Eyring et al. 2016).

The locked simulations were performed in an analogous manner as described in Rädel et al. (2016) and Olonscheck et al. (2019):

1) Key cloud parameters-including cloud-cover fraction and cloud liquid-ice water content at all vertical levels-were saved from a 250-yr-long control simulation at every 2-h radiation call [note that key cloud parameters are saved from just the first 50 years in Rädel et al. (2016)]. 
2) The cloud parameters from the control run were scrambled by randomizing the year assigned to each time step, but not the hour or day. As such, the randomized cloud parameters have the same longterm mean diurnal and seasonal cycles, have no memory from one time step to the next (e.g., output at 0000 UTC 1 January is assigned a different year than output at 0200 UTC 1 January, etc.), and are decoupled from the circulation. As discussed below, the lack of autocorrelation in the cloud fields plays an important role in changing the low-frequency variance of the attendant CREs.

3) The scrambled cloud fields were then read into the radiation code of the locked-clouds simulation at every 2 -h radiation call. The cloud locking method is only applied to the radiative transfer scheme; all other model components use internally simulated clouds.

The control and locked-clouds simulations are both 250 years in length, but the first 50 years of both simulations are discarded to account for the warming adjustment in the locked-clouds simulation as mentioned below. Note that a very similar scrambling methodology is also applied in Grise et al. (2019).

Decoupling the cloud fields from the circulation leads to a weak warm bias in the locked-clouds simulations relative to the control run. A similar global-mean warming or cooling-climate drift is found in other locked-clouds simulations, and is thought to arise from the small artificial radiative forcing that arises from the loss of spatiotemporal structure in clouds (Schneider et al. 1999; Langen et al. 2012; Mauritsen et al. 2013; Rädel et al. 2016; Middlemas et al. 2019; Olonscheck et al. 2019). It is possible that the weak warm bias in the locked simulation could affect the variance of temperature in the polar regions, since the variability in sea ice coverage depends on sea ice thickness. For this reason, results are only shown equatorward of $70^{\circ} \mathrm{S} / \mathrm{N}$ [readers are referred to Olonscheck et al. (2019) for a more detailed discussion on sea ice changes in analogous locking simulations]. However, we view it as unlikely that the small bias in mean temperature in the tropics will have a notable effect on the temperature variance there since the differences in mean temperature between the control and locked simulation are roughly an order of magnitude smaller than the typical differences in mean temperature between the coldest and warmest historical simulations in the CMIP5 archive (Mauritsen et al. 2012).

\section{The influence of cloud radiative effects on tropical SST variability}

We focus our analysis on a comparison of month-tomonth variability in 1) the control simulation, where a) Variance of SST in the interactive-clouds run $\left(\sigma^{2}\right)$

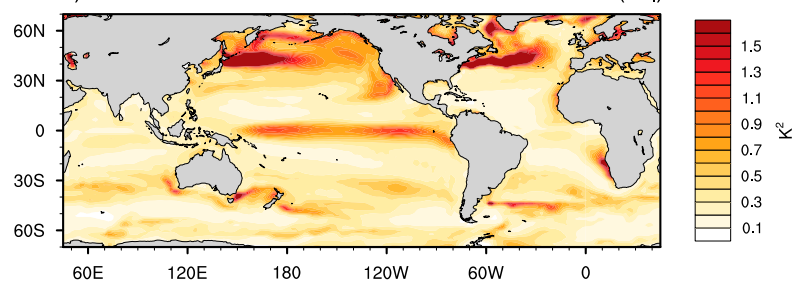

b) Variance of SST in the locked-clouds run $\left(\sigma_{L}^{2}\right)$

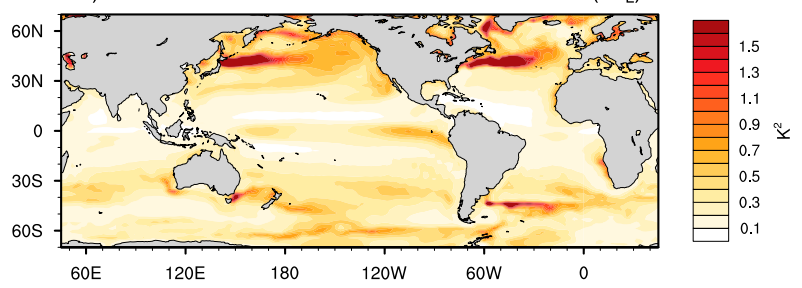

c) $\sigma_{1}^{2} / \sigma_{L}^{2}$

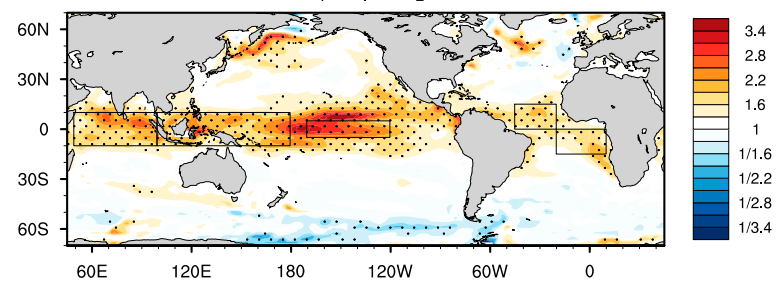

FIG. 1. The effect of interactive clouds on SST variance. (a) Variances of monthly mean SST anomalies from the 200-yr interactive-clouds run. (b) Variances of monthly mean SST anomalies from the 200-yr locked-clouds run. (c) Ratio of the variances between the interactive and locked runs. A ratio $>1$ indicates larger variability in the interactive run, and vice versa. Stippling indicates regions where the ratios are significant at the $95 \%$ level based on the $F$ statistic. The black boxes in (c) are the regions used for calculating the power spectra of the area-averaged SST anomalies in Fig. 2.

clouds are coupled to the circulation (hereafter referred to as the "interactive" clouds run), and 2) the lockedclouds run, where clouds are decoupled from the circulation. The differences in climate variability between the interactive- and locked-clouds simulations derive entirely from the role of coupling between CREs and the circulation.

Figure 1a shows the variance of monthly mean SST anomalies in the interactive-clouds run. The simulated SST variability is most pronounced in regions where 1 ) upwelling is important (e.g., along the equator and near coastal regions) and 2) ocean heat transport and atmospheric temperature advection are important (e.g., the western boundary current regions). Figure $1 \mathrm{~b}$ shows the same results for the locked-clouds run. At first glance, the patterns of SST variance in the control interactiveand locked-clouds runs appear to differ only in the eastern tropical Pacific. But closer inspection of the results reveals marked differences throughout the tropical oceans. 
a) Nino3.4

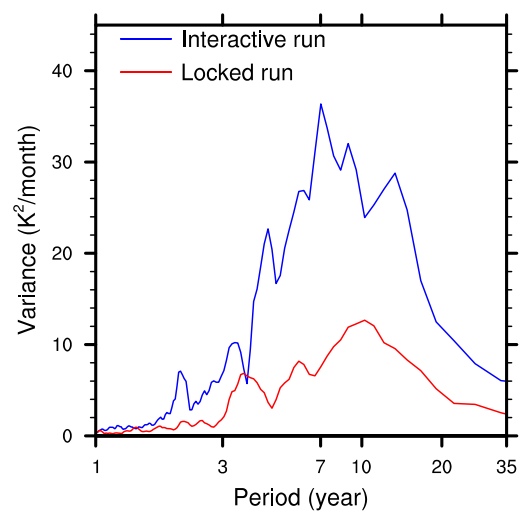

d) Tropical Western Pacific

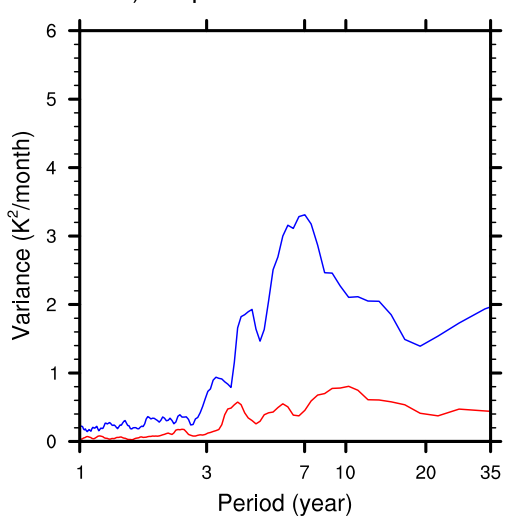

b) Tropical-mean

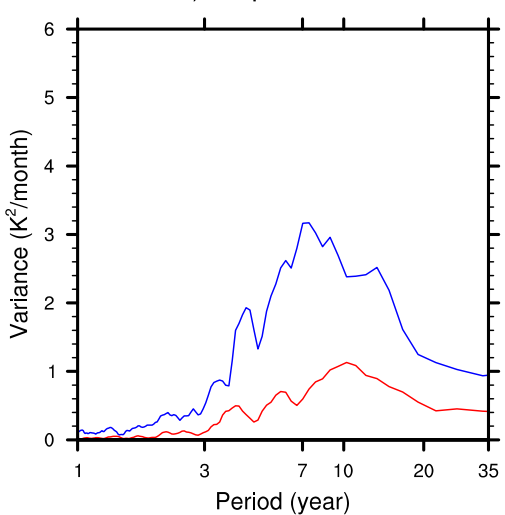

e) Tropical North Atlantic

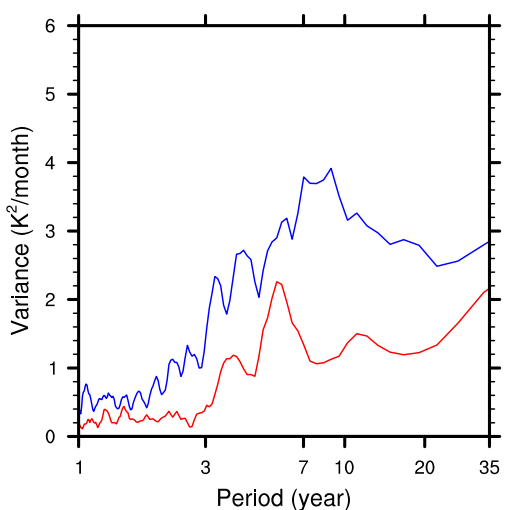

c) Tropical Indian

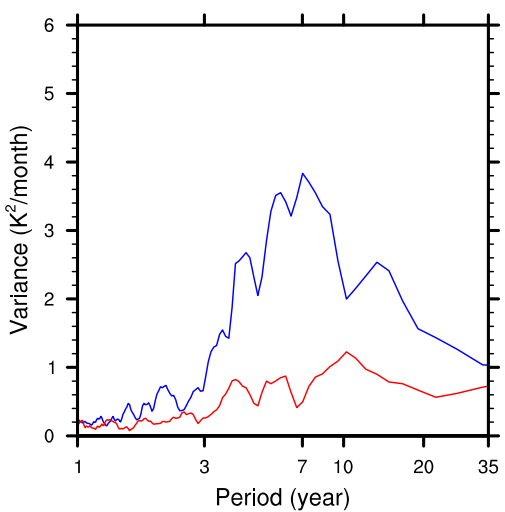

f) Tropical South Atlantic

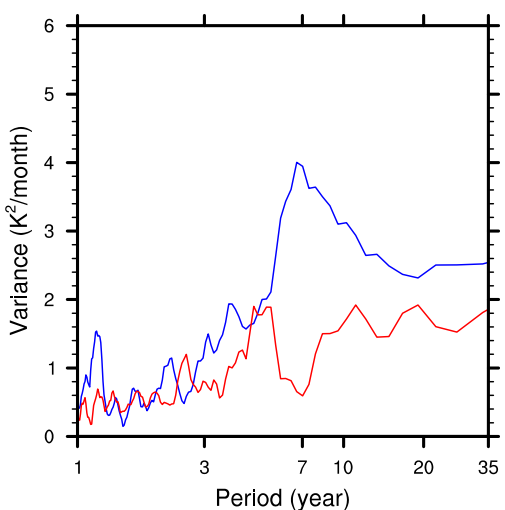

FIG. 2. Power spectra of SST anomaly time series for indicated regions. Power spectra of SST anomaly time series averaged over (a) Niño-3.4, (b) entire tropics $\left(15^{\circ} \mathrm{S}-15^{\circ} \mathrm{N}\right)$, (c) tropical Indian Ocean $\left(10^{\circ} \mathrm{S}-10^{\circ} \mathrm{N}, 50^{\circ}-100^{\circ} \mathrm{E}\right)$, (d) tropical western Pacific $\left(10^{\circ} \mathrm{S}-10^{\circ} \mathrm{N}\right.$, $\left.100^{\circ} \mathrm{E}-180^{\circ}\right)$, (e) tropical North Atlantic $\left(0^{\circ}-15^{\circ} \mathrm{N}, 315^{\circ}-340^{\circ} \mathrm{E}\right)$, and (f) tropical South Atlantic $\left(15^{\circ} \mathrm{S}-0^{\circ}, 20^{\circ} \mathrm{W}-10^{\circ} \mathrm{E}\right)$. Results for the interactive-clouds simulation are indicated by the blue lines and for the locked-clouds simulation are indicated by the red lines. Regions are indicated by the black boxes in Fig. 1c.

Figure 1c shows the ratios of the SST variances in the interactive- and locked-clouds simulations. Values greater than one indicate regions where coupling between CREs and the circulation acts to increase the variance in SSTs, and vice versa. Areas where the variance ratios are statistically significant at the $95 \%$ significance level based on the $F$ statistic are stippled. The most prominent ratios in Fig. 1c are found at tropical latitudes, particularly in the tropical Pacific. The increases in variance over the tropical Pacific are consistent with the amplification of ENSO variability found in Rädel et al. (2016). However, and importantly, similar increases in SST variance are found throughout the tropical oceans, including variance ratios of 2-3 in the tropical Indian and Atlantic Ocean basins.

The differences in area-averaged SST variances between the interactive- and locked-clouds simulations are shown as a function of frequency in the power spectra in Fig. 2. The differences are dramatic. Again, the differences in the power spectra over the Niño-3.4 region (Fig. 2a) are consistent with the increases in ENSO variance noted in Rädel et al. (2016, cf. Fig. 2a) and the shift to higher-frequency ENSO variability found in Middlemas et al. (2019, cf. Fig. 4a). However, the variances in the interactive simulation are increased substantially on interannual and decadal time scale not only in the eastern tropical Pacific, but across the entire tropics (Figs. 2b-f). The increases in variance in the tropical Indian Ocean (Fig. 2c), tropical western Pacific Ocean (Fig. 2d), and tropical North and South Atlantic Ocean (Figs. 2e,f) are most pronounced on time scales longer than $\sim 5$ years. Critically, the increases in tropical SST variance transcend the linear response to the model ENSO (see appendix B). That is, the increases in variances outside the eastern tropical Pacific remain significant after the Niño-3.4 time series is linearly regressed from the output. As argued in section 4, the differences in monthly mean SST variance shown in Fig. 1c (and 

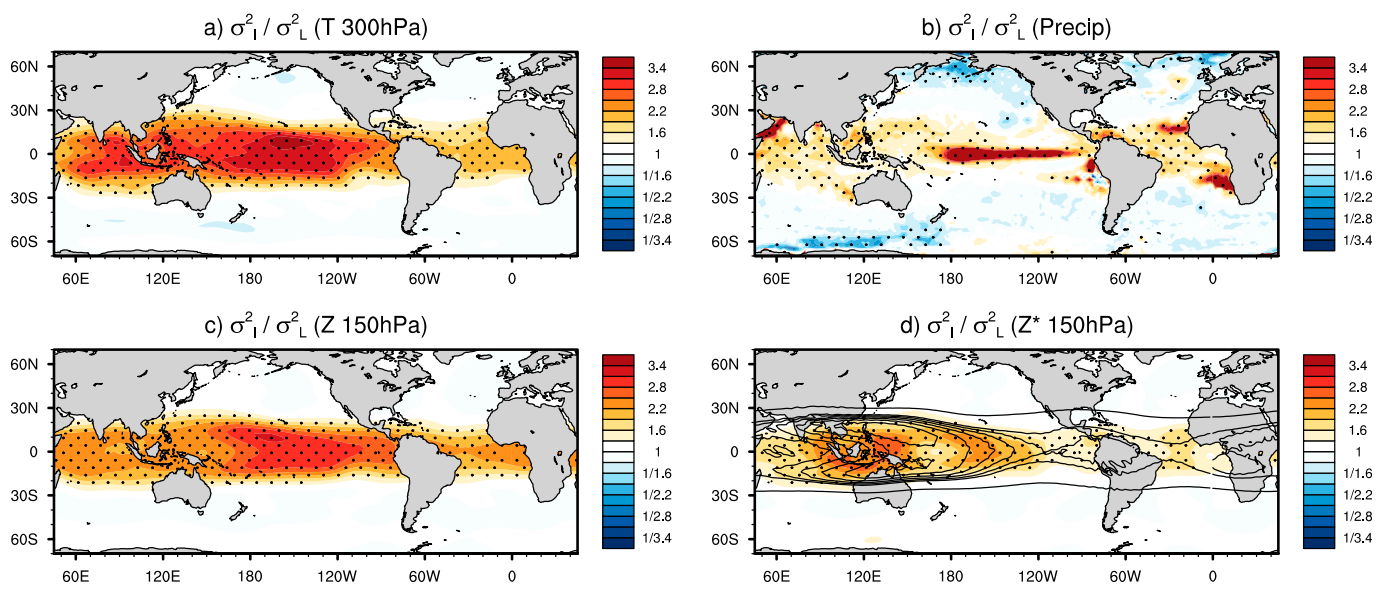

FIG. 3. The effects of interactive clouds on tropical climate. Ratio of the variances between the interactive and locked runs of (a) atmospheric temperature at $300 \mathrm{hPa}$, (b) convective precipitation, (c) geopotential height at $150 \mathrm{hPa}$, and (d) eddy geopotential height at $150 \mathrm{hPa}$. The black contours superimposed in (d) denote the long-term-mean geopotential height at $150 \mathrm{hPa}$ (contours are plotted for 14000,14100,14110,14120,14130 m...). Results in shading are based on monthly mean anomalies. As in Fig. 1, stippling indicates regions where the ratio is significant at $95 \%$ level based on the $F$ statistic.

Fig. B1) arise not from the projection of CREs onto ENSO per se, but rather from a more basic effect of CREs on SST.

The tropicswide increases in SST variance are associated with a range of differences in various other tropical fields. They are associated with increases in the variance of upper-tropospheric temperatures throughout the tropics (Fig. 3a), consistent with the facts that tropical atmospheric temperatures are strongly modulated by the SST field and closely follow the moist adiabatic lapse rate. Rädel et al. (2016) pose that such enhanced variance of atmospheric temperatures in the interactive runs arises via longwave cloud radiative feedbacks. But as discussed in the next section, we have a different interpretation of the source of increased variance.

The tropicswide increases in SST variance are associated with increases in the variances of convective precipitation (Fig. 3b), particularly over the tropical Pacific where the SST variance ratios are largest. And they are associated with increases in the variances of the upper-tropospheric geopotential height field (Fig. 3c). The increases in the variance of upper-tropospheric geopotential height project onto the structure of the model equatorial planetary waves, as evidenced by the close correspondence between 1) the equatorial troughs and ridges in the climatological-mean geopotential height field (black contours in Fig. 3d) and 2) the variance ratios in the eddy geopotential height field (shading in Fig. 3d).

\section{Interpretation}

Figures 1 and 2 reveal marked increases in SST variance throughout the tropics in simulations run with interactive CREs. In this section, we explore the role of CRE in driving the tropical SST variability in the context of surface energy budget rather than in the context of specific modes of climate variability.

\section{a. Surface energy budget}

The energy budget for the surface mixed layer of the ocean can be expressed in monthly mean anomaly form as

$C_{o} \frac{\partial T^{\prime}}{\partial t}=Q_{\mathrm{SW}}^{\prime}+Q_{\mathrm{LW}}^{\prime}+Q_{\mathrm{LH}}^{\prime}+Q_{\mathrm{SH}}^{\prime}+Q_{\mathrm{EK}}^{\prime}+Q_{\mathrm{geo}}^{\prime}$,

where primes denote monthly mean anomalies (departures from the long-term mean seasonal cycle); $T^{\prime}$ is the anomalous temperature of the mixed layer (assumed proportional to the anomalous SST); $C_{o}$ is the effective heat capacity of the mixed layer $\left(C_{o}=C_{p} \rho h\right.$, in which $\rho$ and $C_{p}$ are the density and specific heat capacity at constant pressure of the seawater, i.e., $3850 \mathrm{~J} \mathrm{~kg}^{-1} \mathrm{~K}^{-1}$ and $h$ is the annual-mean mixed layer depth taken from the ocean model); and the $Q^{\prime}$ are the heatings due to anomalous surface shortwave radiative flux $Q_{\mathrm{SW}}^{\prime}$, longwave radiative flux $Q_{\mathrm{LW}}^{\prime}$, latent heat flux $Q_{\mathrm{LH}}^{\prime}$, sensible heat flux $Q_{\mathrm{SH}}^{\prime}$, advection by the Ekman flow $Q_{\mathrm{EK}}^{\prime}$, and advection by the surface geostrophic flow $Q_{\mathrm{geo}}^{\prime}$. Here, $Q_{\mathrm{EK}}=-C_{o} \mathbf{V}_{\mathrm{EK}} \cdot \nabla T$ and $Q_{\text {geo }}=-C_{o} \mathbf{V}_{\text {geo }} \cdot \nabla T$, in which $\mathbf{V}_{\mathrm{EK}}$ is the Ekman flow induced by the wind stress $\tau$ and $\mathbf{V}_{\text {geo }}$ is the geostrophic currents. We neglect vertical advection and entrainment (Xie 1999) even though these processes are clearly important along the coastal and equatorial upwelling zones. 
Following Yu and Boer (2006), we can quantify the physical factors that drive the increases in SST variance by diagnosing the attendant changes in the surface energy budget of Eq. (1). Specifically, Eq. (1) can be manipulated to yield an expression for the temperature variance by 1) taking the centered difference of Eq. (1), 2) squaring the result, and 3) taking the time mean. As reviewed in appendix A, the above operation yields the following expression for the temperature variance:

$$
\sigma_{T}^{2}=G \sigma_{\Sigma}^{2} e,
$$

where

- $\sigma_{T}^{2}$ is the variance of the SST field.

- $\sigma_{\Sigma}^{2}=\sigma_{\mathrm{SW}}^{2}+\sigma_{\mathrm{LW}}^{2}+\sigma_{\mathrm{LH}}^{2}+\sigma_{\mathrm{SH}}^{2}+\sigma_{\mathrm{EK}}^{2}+\sigma_{\mathrm{geo}}^{2}$ is the sum of the variances of the surface heat fluxes and ocean heat transport. Larger variances in the flux and transport terms lead to larger variance in the SST field, and vice versa.

- $e$ includes the sum of the covariances between the heat flux terms \{e.g., $e=1+2 \sum\left[\operatorname{cov}\left(Q_{i}, Q_{j}\right)\right] / \sigma_{\Sigma}^{2}$, where $\sum\left[\operatorname{cov}\left(Q_{i}, Q_{j}\right)\right]=\operatorname{cov}\left(Q_{\mathrm{SW}}^{\prime}, Q_{\mathrm{LH}}^{\prime}\right)+\operatorname{cov}\left(Q_{\mathrm{SW}}^{\prime}, Q_{\mathrm{SH}}^{\prime}\right)+$ $\left.\operatorname{cov}\left(Q_{\mathrm{SW}}^{\prime}, Q_{\mathrm{EK}}^{\prime}\right)+\cdots\right\}$; $e$ may be viewed as an "efficiency factor" that measures the extent to which the variances in the flux and transport terms operate independently in modifying the SST variance ( $\mathrm{Yu}$ and Boer 2006).

- $G=2(\Delta t)^{2} / C_{o}^{2}\left(1-r_{2}\right)$ may be viewed as a "transfer factor" that accounts for the effects on the temperature variance of the sampling time scale $\Delta t$, the persistence (related to lag-2 autocorrelation $r_{2}$ ), and the effective heat capacity $C_{o}$ (Yu and Boer 2006).

The left and center columns in Fig. 4 explore the contributions of the individual terms in $\sigma_{\Sigma}^{2}$ to the variances in monthly mean SSTs in the interactive and locked simulations. The right column shows the percent contributions of the individual variances in the left column to the total variances in the interactive run. The primary features in the figure are the following:

1) The largest variances in the surface energy budget are found in association with the latent heat fluxes and are located over the subtropical and midlatitude oceans (Figs. 4g,h).

2) The variances in the ocean heat transport peak over regions where the climatological-mean SST gradients are largest (Figs. 4m,n) (Alexander 1992), and the variances in the sensible heat fluxes peak over the western sides of the Northern Hemisphere ocean basins (Figs. 4j,k), where there is commonly cold advection in the atmosphere from the continents upstream (Davis 1976; Miller 1992; Alexander 1992;
Cayan 1992; Marshall et al. 2001; Alexander et al. 2002).

3) In the interactive simulation, the variances in the surface shortwave radiative fluxes have relatively similar amplitude across the globe (Fig. 4a). As evidenced in Fig. $4 \mathrm{c}$ and discussed further below, the shortwave radiative fluxes account for a comparatively large fraction of the total variance in the energy budget over the tropics since the latent heat fluxes variance are weakest there. The variances in the longwave radiative fluxes are relatively small and account for a small fraction of the surface flux variance everywhere (Figs. 4d,f).

4) By far the most pronounced differences between the interactive and locked simulations are found in the variances of the shortwave fluxes. The variances in monthly mean shortwave heat fluxes are $\sim 200 \mathrm{~W}^{2} \mathrm{~m}^{-4}$ throughout much of the globe when clouds are coupled to the circulation (Fig. 4a), but less than $\sim 20 \mathrm{~W}^{2} \mathrm{~m}^{-4}$ in the locked simulation (Fig. 4b). As such the shortwave variance ratios $\left(\sigma_{\text {SW interactive }}^{2} / \sigma_{\text {SWlocked }}^{2}\right)$ are as large as $\sim 10$ throughout much of the globe.

The surface radiative flux is derived from the all-sky radiative flux; the variances in clear-sky radiative flux are of similar amplitude between the control and locked simulations. As discussed below, such reduced variance of the monthly mean all-sky shortwave radiative flux in the locked simulation arises from the "whitening" of CREs when clouds are decoupled from the circulation. That is, decoupling clouds from the circulation increases their variance on subdaily time scales but decreases their variance on weekly and longer time scales.

From Eq. (2), it follows that the ratios of temperature variance between the interactive and locked run can be diagnosed as

$$
\frac{\sigma_{T \_ \text {interactive }}^{2}}{\sigma_{T \_ \text {locked }}^{2}}=\frac{\sigma_{\Sigma \_ \text {interactive }}^{2}}{\sigma_{\Sigma \_ \text {locked }}^{2}} \frac{e_{\text {interactive }}}{e_{\text {locked }}} \frac{G_{\text {interactive }}}{G_{\text {locked }}}
$$

Based on the results shown in Fig. 4, we assume 1) the variances associated with the shortwave and longwave radiative flux in the locked-clouds run are very small (Figs. 4b,e), 2) the variances associated other terms in the surface energy budget in the locked-clouds runs are approximately equal to those in the interactive run (cf. Figs. 4g,h,j,k,m,n), and 3) the percentage contributions from the longwave radiative flux to the total variance can be neglected (Fig. 4f). Based on the above, the first term in the rhs of Eq. (3) can be written as 
Variances in the interactive-clouds run

a) $\sigma_{\mathrm{SW}}^{2}$

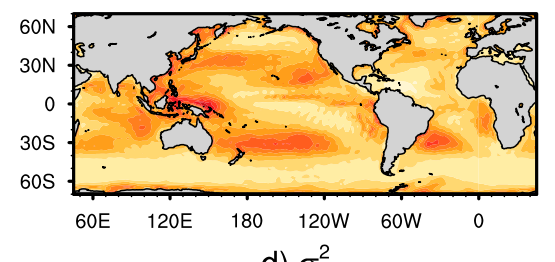

d) $\sigma_{L W}^{2}$

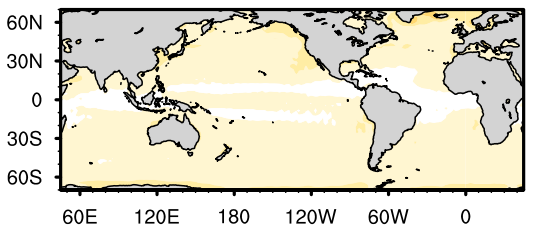

g) $\sigma_{\mathrm{LH}}^{2}$
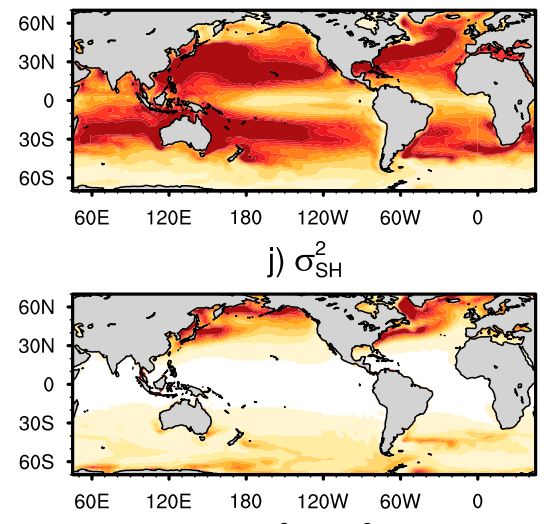

m) $\sigma_{\mathrm{EK}}^{2}+\sigma_{\mathrm{geo}}^{2}$

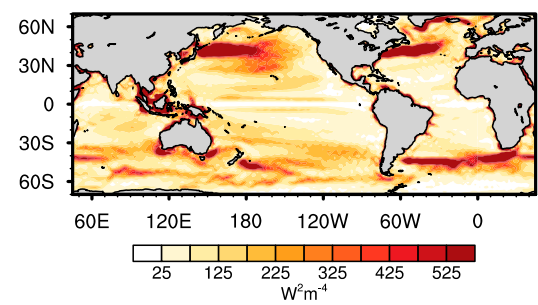

Variances in the locked-clouds run

b) $\sigma_{\mathrm{SW}}^{2}$

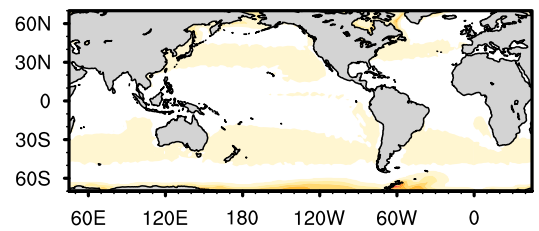

e) $\sigma_{L W}^{2}$

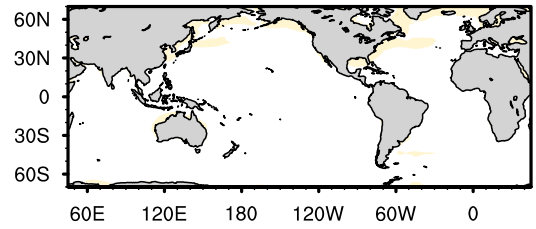

h) $\sigma_{\mathrm{LH}}^{2}$
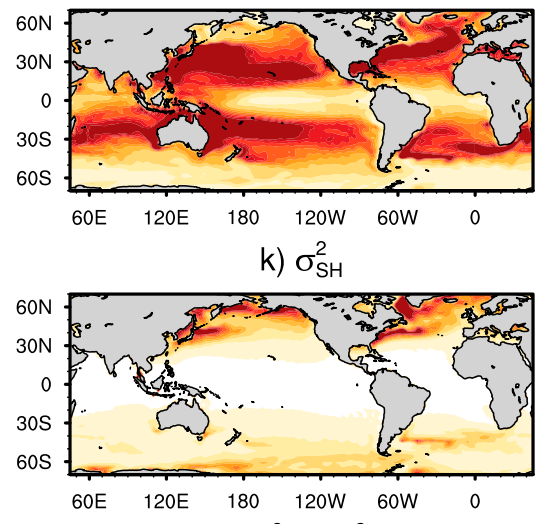

n) $\sigma_{\mathrm{EK}}^{2}+\sigma_{\mathrm{geo}}^{2}$

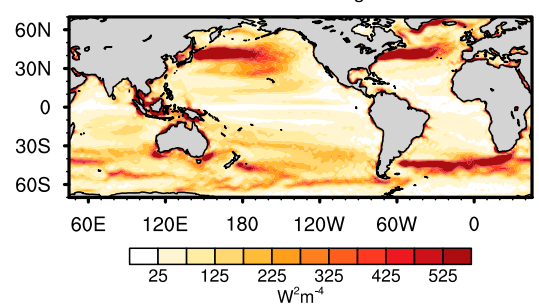

Percentage contributions to $\sigma_{\Sigma}^{2}$ in the interactive-clouds run

$$
\text { c) } \sigma_{\mathrm{SW}}^{2} / \sigma_{\Sigma}^{2}
$$

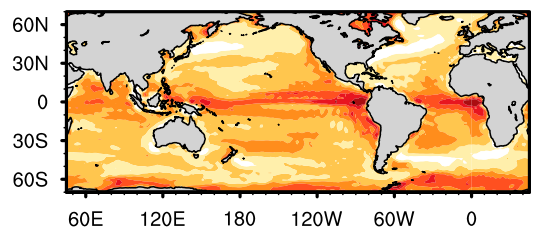

f) $\sigma_{\mathrm{LW}}^{2} / \sigma_{\Sigma}^{2}$

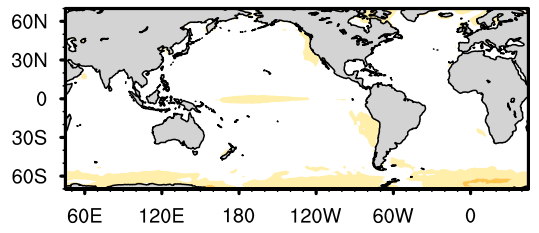

i) $\sigma_{L H}^{2} / \sigma_{\Sigma}^{2}$
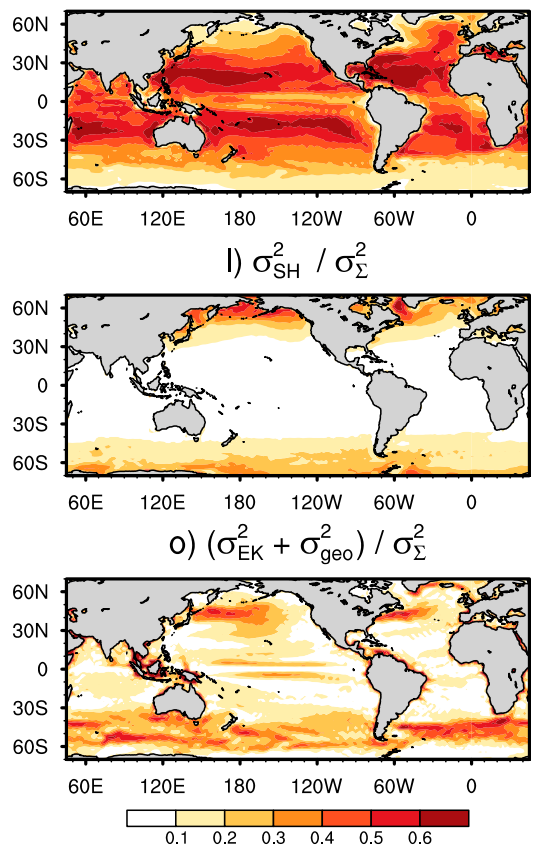

FIG. 4. Variances in the surface energy fluxes: (a),(b) surface shortwave radiative flux, (d),(e) longwave radiative flux, (g),(h) latent heat flux, (j),(k) sensible heat flux, and (m),(n) heat advection by the meridional Ekman and geostrophic current. Results are for (left) the 200 -yr interactive-clouds simulation and (center) the 200-yr locked-clouds simulation. (right) Percentage contribution of each term to the total variance in the interactive-clouds simulation. Results are based on monthly mean anomalies.

$$
\begin{aligned}
\frac{\sigma_{\Sigma_{-} \text {interactive }}^{2}}{\sigma_{\Sigma_{-} \text {locked }}^{2}} & \approx \frac{\sigma_{\Sigma_{-} \text {interactive }}^{2}}{\left(\sigma_{\mathrm{LH}}^{2}+\sigma_{\mathrm{SH}}^{2}+\sigma_{\mathrm{EK}}^{2}+\sigma_{\text {geo }}^{2}\right)_{\text {interactive }}} \\
& \approx \frac{1}{1-\left(\frac{\sigma_{\mathrm{SW}}^{2}}{\sigma_{\Sigma}^{2}}\right)_{\text {interactive }}} .
\end{aligned}
$$

The simple scaling in Eq. (4) suggests that 1) the changes in the total variance of the surface energy flux between the interactive- and locked-clouds simulations [lhs of
Eq. (4)] should peak over regions where 2) the shortwave cloud flux variance makes the largest contribution to the total energy flux variance in the interactive simulation (i.e., as shown in Fig. 4c).

Figure 5 quantifies the contributions of the various ratios in Eqs. (3) and (4) to the changes in temperature variance between the interactive and locked simulations. Figure 5a reproduces the ratios of the temperature variances from Fig. 1c [i.e., it shows the lhs of Eq. (3)]. Figure $5 \mathrm{~b}$ shows the product of the ratios between the 


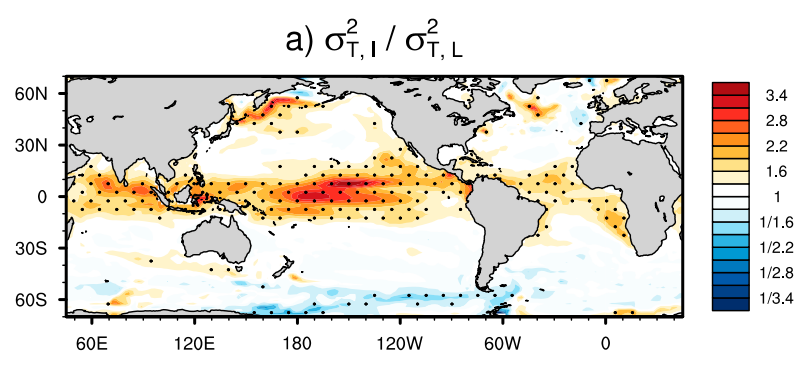

b) $\left(\sigma_{\Sigma, 1}^{2} / \sigma_{\Sigma, \mathrm{L}}^{2}\right) \cdot\left(e_{\mathrm{I}} / e_{\mathrm{L}}\right) \cdot\left(G_{\mathrm{I}} / G_{\mathrm{L}}\right)$

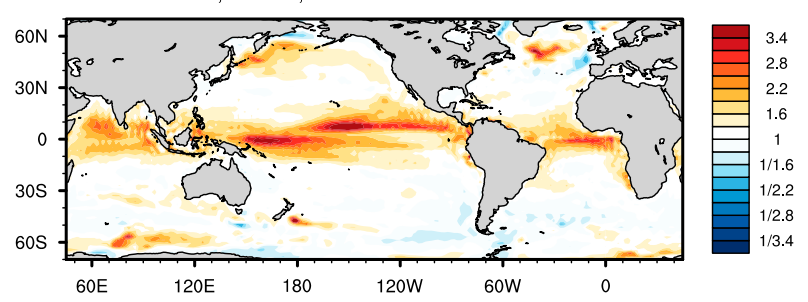

c) $\sigma_{\Sigma, 1}^{2} / \sigma_{\Sigma, L}^{2}$

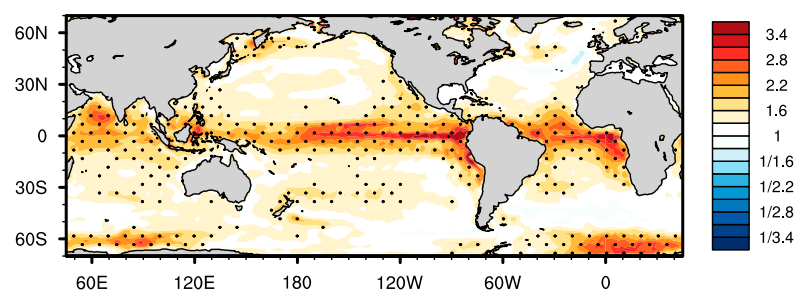

d) $1 /\left(1-\sigma_{\mathrm{SW}, 1}^{2} / \sigma_{\Sigma, 1}^{2}\right)$

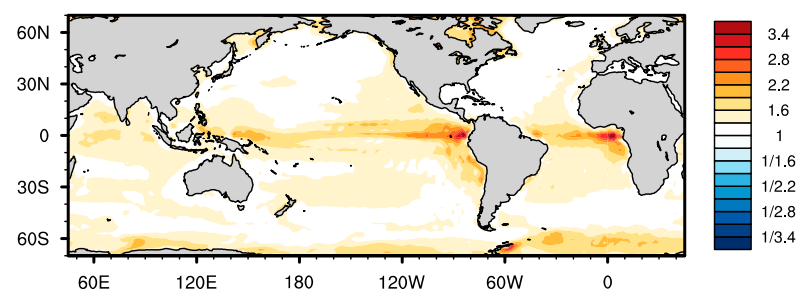

FIG. 5. Identifying the physical factors responsible for the increases in SST variance. (a) The ratios of the surface temperature variance between the interactive and locked simulations (reproduced from Fig. 1c). (b) The product of all three terms on the rhs of Eq. (3). (c) The contribution of the ratios in the sums of the surface fluxes [the first factor on the rhs of Eq. (3)]. (d) The results of the approximation in Eq. (4), which highlights the dominant role of the SW radiative fluxes in the ratios shown in (c) (see text for details). Results are based on monthly mean anomalies. As in Fig. 1, stippling indicates regions where the ratio is significant at $95 \%$ level based on the $F$ statistic.

interactive and locked simulations of 1) the surface flux and transport variances, 2) the efficiency factors $e$, and 3) transfer factors $G$ [i.e., it shows the rhs of Eq. (3)]. Figure $5 \mathrm{c}$ shows the first factor only from the rhs of Eq. (3), which is equivalent to the sum of the results in the left column in Fig. $4\left(\sigma_{\Sigma}^{2}\right.$ interactive $)$ divided by the sum of the results in the center column $\left(\sigma_{\Sigma \_ \text {locked }}^{2}\right)$. Figures $5 \mathrm{c}$ and $5 \mathrm{~d}$ show the results of the scaling approximation from Eq. (4), and highlight the role of the shortwave radiative fluxes.

Comparing the results in Figs. 5a-c, it is clear that the ratios of SST variances between the interactive and locked simulations (Fig. 5a) can be qualitatively reproduced by the decomposition given in Eq. (3) (Fig. 5b). The decomposition, in turn, is dominated by the first factor on the rhs of Eq. (3). That is, the increases in SST variance in the interactive simulation arise primarily from the increases in the variance of the surface energy fluxes (Fig. 5c). The other two factors on the rhs of Eq. (3) (i.e., the efficiency and transfer factors) are dominated by 1 ) decreases in the covariances between the radiative fluxes in the locked run and 2) weak increases in SST persistence in the tropical and extratropical oceans in the interactive run (see Fig. $\mathrm{C} 1$ in appendix C). However, they play a relatively small role in the amplification of tropical SST variance between the interactive and locked simulations, as evidenced by the similarities between Figs. 5b and 5c. The fact that the differences in SST variance between the interactive and locked simulations peak at tropical latitudes (Fig. 5a) is consistent with the fact that the shortwave radiative fluxes play a more prominent role in the total variance of the surface energy fluxes at tropical latitudes than they do at extratropical latitudes [Figs. 4c and 5d; Eq. (4)].

The key results in Figs. 4 and 5 are thus

1) the preponderance of the differences in monthly mean SST variance between the interactive and locked simulations (Fig. 1c) arise from the attendant differences in the monthly mean shortwave radiative flux variances (Figs. 4a,b), and

2) the differences in monthly mean SST variance peak in the tropics (Fig. 1c) since the variance in the shortwave radiative fluxes accounts for a relatively large fraction of the total variances in the surface energy budget there (Figs. 4c, 5d).

\section{b. Relationships between the hour-to-hour persistence and month-to-month variance of cloud fraction}

Why does the variance of the monthly mean shortwave radiative flux increase when clouds are coupled to the atmospheric circulation? To understand this, we first consider the power spectrum of two standardized, random time series: 1) a white noise time series and 2) a red noise time series with lag- 1 autocorrelation of $r_{1}=0.9$. For the purpose of comparison to the numerical model output, the increment between time steps is defined as $2 \mathrm{~h}$. By construction, both time series have the same variance: one. However, the white noise time series has larger variance than the red noise time series at periods shorter than $\sim 28 \mathrm{~h}$ (i.e., 14 time steps), whereas the red 
noise time series has much larger variance than the white noise time series at all periods longer than $\sim 28 \mathrm{~h}$ (Fig. 6a). The cutoff period at which a standardized red noise time series exhibits larger variance than a standardized white noise time series ranges from $\sim 14$ time steps (i.e., $28 \mathrm{~h}$ in the case of data sampled every $2 \mathrm{~h}$ ) when $r_{1}=0.9$ to about five time steps (i.e., $10 \mathrm{~h}$ ) when $r_{1}=0.1$ (see dashed lines in Fig. 6a).

Now consider the time series of total cloud fraction at a sample tropical grid point from the control interactive model simulations sampled at 2-hourly intervals (corresponding to radiation call). In the interactive simulation, the cloud fraction has memory from one radiation call (every $2 \mathrm{~h}$ ) to the next of roughly $r_{1} \approx 0.9$. However, in the locked simulation - by construction - the cloud fraction has no memory from 2 -h period to the next $\left(r_{1}=0\right)$. The total variance of the cloud fraction time series is identical in both the interactive and locked simulations. However, as is the case for the idealized white and red noise time series, the differences in the variance of cloud fraction between the two simulations are a function of frequency. The variance of cloud fraction in the interactive simulation is less than the variance of cloud fraction in the locked simulation at periods less than $\sim 24 \mathrm{~h}$, but exceeds the variance of cloud fraction in the locked simulation at periods greater than $\sim 1$ day (Fig. $6 b$ ).

Hence, the increases in the variances of cloud fraction-and thus in the variances in shortwave CREs (Figs. 4a-c) and SSTs (Fig. 5) - in the interactive simulations arise from the reddening of the cloud field when it is coupled to the atmospheric circulation. A basic effect of two-way coupling between clouds and the atmospheric circulation in the simulation is thus to increase the variance of CREs on time scales longer than a few days at the expense of shorter time scales. As noted earlier, the increased variances in shortwave CREs have largest effect on the variance in SSTs at tropical latitudes, where the shortwave radiative fluxes account for a large fraction of the total variance in the surface energy fluxes. They have only a weak effect on the variances in SSTs at extratropical latitudes, where the shortwave radiative fluxes play a small role in the total variance in the surface energy fluxes.

\section{Concluding remarks}

It is long established that CREs play a central role in determining Earth's mean climate. It is becoming increasingly clear that they also play a key role in Earth's climate variability across a range of time scales. In two recent studies, Rädel et al. (2016) and Middlemas et al. (2019) argue that the inclusion of coupling between the
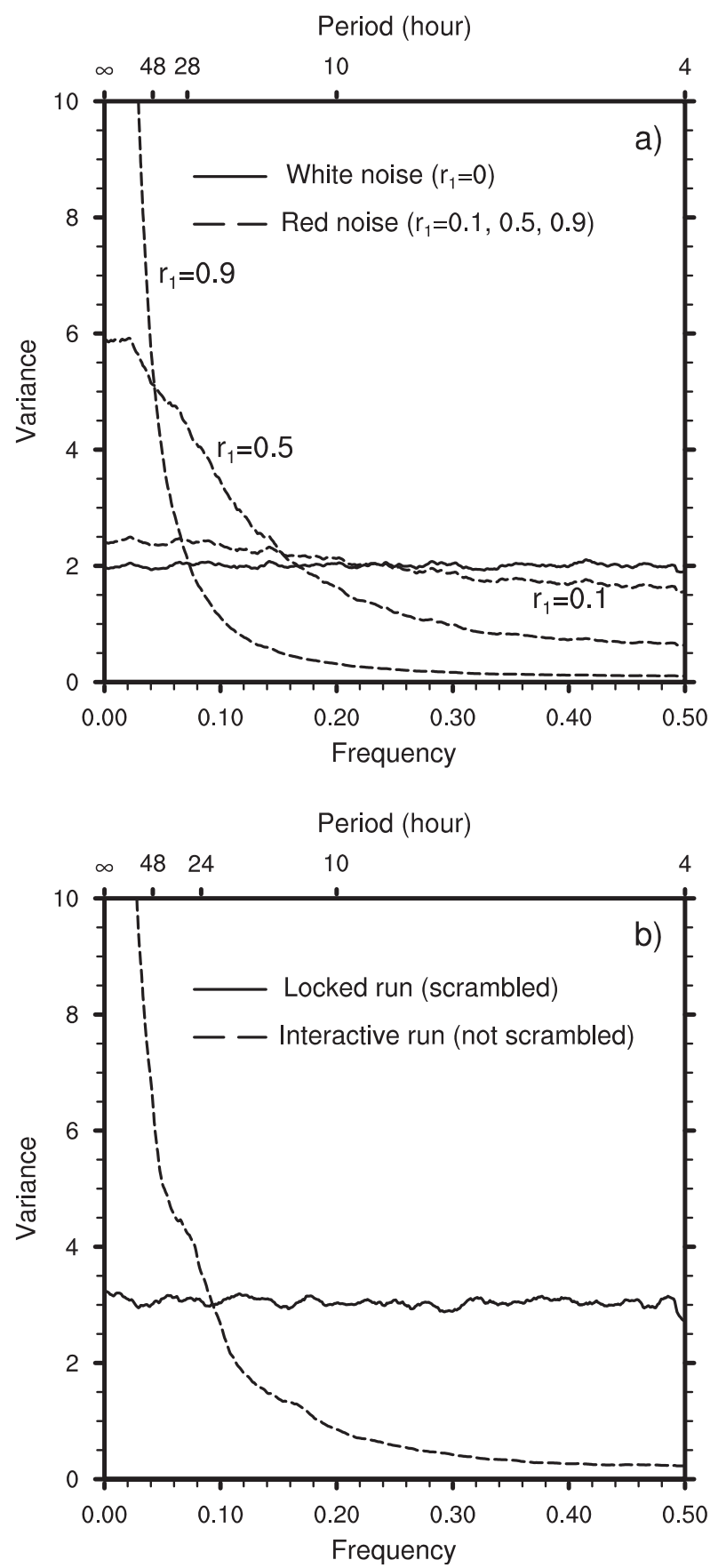

FIG. 6. The importance of persistence in the variance of cloud fraction. (a) Power spectra for a randomly generated red noise time series with lag- 1 autocorrelations of $r_{1}=0.9,0.5$, and 0.1 (dashed lines) and a white noise time series with $r_{1}=0$ (solid line). (b) Power spectra for time series of cloud fraction at a sample tropical grid point $\left(0^{\circ}, 180^{\circ}\right)$ used in the interactive-clouds run (dashed line) and the locked-clouds run (solid). The cloud fraction time series are 50 years long and sampled at 2 -hourly intervals. The randomly generated time series used to construct (a) are the same length and same time-step interval as the cloud fraction time series. 
atmospheric circulation and clouds projects onto the variance of the ENSO, primarily due to the projection of longwave or shortwave CREs onto ENSO physics. Here we argue that coupling between the atmospheric circulation and CREs leads to a much broader and more basic effect on the climate system: Cloud circulation coupling leads to increases in the variance of SSTs on time scales from months to decades that are apparent throughout the tropical oceans (Figs. 1c, 2) and cannot be explained as the linear response to simulated ENSO variability (appendix B).

We hypothesize that the increases in tropical SST variance in the interactive simulation arise from the "reddening" of shortwave CREs when clouds are coupled to the circulation. Coupling between the atmospheric circulation and clouds increases the memory in clouds on subdaily and day-to-day time scales (e.g., the $e$-folding time scale of cloud fraction is $\sim 1-2$ days in sample time series drawn from the interactive simulation; Fig. 6b). The reddening of the cloud field due to the memory inherent in the large-scale atmospheric circulation leads to a reduction in the variance of cloud fraction on time scales less than a few days but large increases in the variance of cloud fraction on time scales greater than a few days (Fig. 6). Decomposition of the surface energy budget (Figs. 4, 5) reveals that it is the resulting increases in the variance of monthly mean shortwave CREs that lead to the increases in SST variance when clouds are coupled to the circulation. The increases in SST variance are most clear in the tropics, where the shortwave heat fluxes account for the largest fraction of the total variance in the surface energy budget (Figs. 4c, 5d). They are less clear in the extratropics, where SST variability is dominated by the surface turbulent heat fluxes (Fig. 4i).

The hypothesis accounts for enhanced SST variability on time scales spanning months to decades throughout the tropical oceans when clouds are coupled to the atmospheric circulation. A key assumption in the hypothesis is that cloud-circulation coupling does not change the total variance in clouds and CREs (i.e., by construction, the total variance is held fixed in the locked- and interactive-cloud simulations). Rather, cloud-circulation coupling is theorized to impart memory to-and thus enhance the low-frequency variance of-clouds and their radiative effects. Such memory would not exist in the absence of the coupling of clouds to large-scale dynamics.

The results shown here support our hypothesis that the reddening of shortwave CREs by cloud-circulation feedbacks leads to a reddening of SST variability. It is difficult to quantitatively compare our results with those published in Middlemas et al. (2019) without reproducing their simulations in the climate model used here. Hence, it is unclear whether the differences in results between our study and that study arises from differences in 1) the locking methodologies or 2) the cloud radiative feedbacks and cloud-circulation coupling schemes used in the different climate models. It would be interesting to further test our hypothesis by running additional simulations on the MPI climate model in which the cloud fields are 1) decoupled from the circulation but 2) retain the same autocorrelation. It would also be interesting to explore and test the robustness of our hypothesis in climate models with different representations of CREs and in geographic regions corresponding to different convective regimes (i.e., cloud-circulation coupling is a function of convective regime; Bony and Dufresne 2005). We plan to test our hypothesis in more detail in a companion study.

The results shown here reveal the remarkable effect that cloud-circulation coupling has on the amplitude of SST variability on intraseasonal, interannual, and even decadal time scales (Figs. 1c, 2). Hence, a key implication of our hypothesis is that the amplitude of SST variability in numerical simulations depends critically on model renditions of CREs and cloud-circulation coupling. This is important, since tropical SSTs provide a source of potential predictability for the climate system across a range of time scales and are linked to a host of surface climate impacts throughout the tropics and extratropics. The implications of our hypothesis for climate impacts and predictability are being explored for a companion study.

Acknowledgments. We thank Thorsten Mauritsen for assistance with the numerical model output. We gratefully acknowledge three anonymous reviewers whose insightful comments led to significant improvements to the manuscript. We also thank Eleanor A. Middlemas and Kevin M. Grise for providing comments and suggestions. Y.L. is funded by NSF Climate and Large-Scale Dynamics (AGS-1547003) and NASA JPL (1439268). D.W.J.T. is funded by NSF Climate and Large-Scale Dynamics (AGS-1343080 and AGS-1547003). D.O. is funded by the Max Planck Society (MPG). We thank the German Climate Computing Centre (DKRZ) for providing extensive computational resources.

\section{APPENDIX A}

\section{Decomposition of the Factors that Contribute to the Variance in SST}

The variance of SST is derived from the surface energy equation [Eq. (1)], and follows Yu and Boer (2006). Taking the centered difference of Eq. (1), 


$$
\begin{aligned}
C_{o} & \frac{T^{\prime}(t+\Delta t)-T^{\prime}(t-\Delta t)}{2 \Delta t} \\
& =Q_{\mathrm{SW}}^{\prime}+Q_{\mathrm{LW}}^{\prime}+Q_{\mathrm{LH}}^{\prime}+Q_{\mathrm{SH}}^{\prime}+Q_{\mathrm{EK}}^{\prime}+Q_{\mathrm{geo}}^{\prime},
\end{aligned}
$$

where $\Delta t$ is 1 month.

Taking the square of Eq. (A1) and the time average (denoted by overbar), the lhs of the resulting equation is approximately equal to

$$
\begin{gathered}
\frac{C_{o}^{2}}{2(\Delta t)^{2}}\left[\overline{T(t)^{2}}-\overline{T^{\prime}(t+\Delta t) T^{\prime}(t-\Delta t)}\right] \\
=\frac{C_{o}^{2}\left(1-r_{2}\right)}{2(\Delta t)^{2}} \sigma_{T}^{2},
\end{gathered}
$$

where $\sigma_{T}^{2}$ is the variance of the monthly mean SST anomaly, and $r_{2}$ is lag-2 autocorrelation of SST anomaly computed as $\overline{T^{\prime}(t+\Delta t) T^{\prime}(t-\Delta t)} / \overline{T(t)^{\prime 2}}$.

The rhs of the square and time average of Eq. (A1) is equal to

$$
\sigma_{\Sigma}^{2}+2 \sum\left[\operatorname{cov}\left(Q_{i}, Q_{j}\right)\right]
$$

where $\sigma_{\Sigma}^{2}$ is the total variances of the six heat fluxes and transport-related variances $\left(\sigma_{\Sigma}^{2}=\sigma_{\mathrm{SW}}^{2}+\sigma_{\mathrm{LW}}^{2}+\right.$ $\left.\sigma_{\mathrm{LH}}^{2}+\sigma_{\mathrm{SH}}^{2}+\sigma_{\mathrm{EK}}^{2}+\sigma_{\mathrm{geo}}^{2}\right)$, and $\sum\left[\operatorname{cov}\left(Q_{i}, Q_{j}\right)\right]$ is the summed covariances of the individual six components $\left\{\sum\left[\operatorname{cov}\left(Q_{i}^{\prime}, Q_{j}^{\prime}\right)\right]=\operatorname{cov}\left(Q_{\mathrm{SH}}^{\prime}, Q_{\mathrm{LH}}^{\prime}\right)+\operatorname{cov}\left(Q_{\mathrm{SH}}^{\prime}, Q_{\mathrm{SW}}^{\prime}\right)+\right.$ $\left.\operatorname{cov}\left(Q_{\mathrm{SH}}^{\prime}, Q_{\mathrm{EK}}^{\prime}\right)+\cdots\right\}$. Note that the variances and covariances terms involving the radiation fluxes are approximately zero in the locked-clouds simulation (e.g., Figs. 4b,e).

Thus the variance of the SST can be approximately estimated from Eqs. (A2) and (A3) as

$$
\begin{aligned}
\sigma_{T}^{2} & =\frac{2(\Delta t)^{2}}{C_{o}^{2}\left(1-r_{2}\right)}\left\{\sigma_{\Sigma}^{2}+2 \sum\left[\operatorname{cov}\left(Q_{i}, Q_{j}\right)\right]\right\} \\
& =G \sigma_{\Sigma}^{2} e,
\end{aligned}
$$

where $G=2(\Delta t)^{2} /\left[C_{o}^{2}\left(1-r_{2}\right)\right]$, and $e=1+\left\{2 \sum\left[\operatorname{cov}\left(Q_{i}\right.\right.\right.$, $\left.\left.\left.Q_{j}\right)\right] / \sigma_{\Sigma}^{2}\right\}$.

\section{APPENDIX B}

\section{The Robustness of the Changes in SST Variance to Changes in ENSO Variability}

Figures $1 \mathrm{c}$ and 2 reveal that coupled CREs leads to increases in SST variance not only in the tropical centraleastern Pacific but also in the tropical western Pacific and tropical Indian and Atlantic Oceans. Figure B1 tests

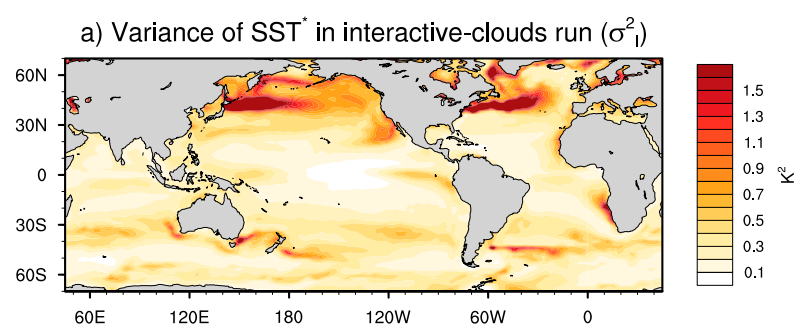

b) Variance of $\mathrm{SST}^{*}$ in locked-clouds run $\left(\sigma^{2}\right)$

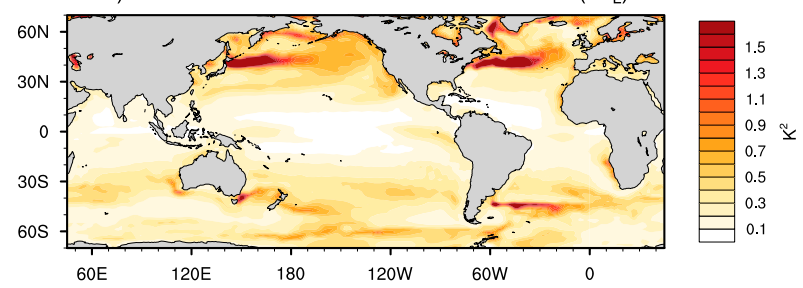

c) $\sigma_{1}^{2} / \sigma_{L}^{2}$

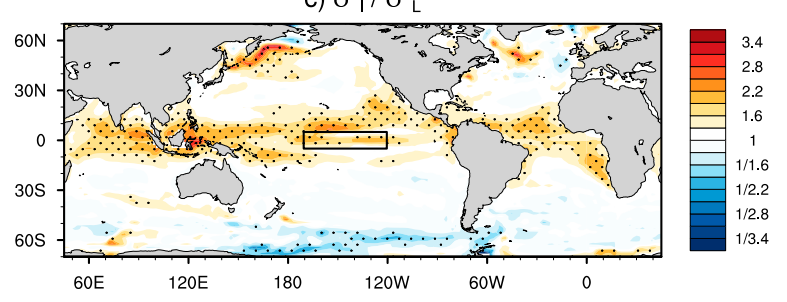

FIG. B1. As in Fig. 1, but for results after linearly removing the Niño-3.4 index [SSTs averaged over $5^{\circ} \mathrm{N}-5^{\circ} \mathrm{S}, 170^{\circ}-120^{\circ} \mathrm{W}$; see black box in (c)] from the SST data at all grid points.

whether the changes in SST variance outside the centraleastern tropical Pacific can be explained as a linear response to SST anomalies in the ENSO region. The figure is identical to Fig. 1, except that the Niño-3.4 index has been linearly regressed from the SST data at every grid point. The regression is based on contemporaneous values of the SST field and the ENSO index, but similar results are derived after lagging the SST field by three months and with other ENSO indices (not shown). By construction, the regression does not account for nonlinear relationships between ENSO variability and the SST field. As illustrated in Fig. B1, the increases in SST variances outside the eastern tropical Pacific are not linearly related to changes in SST variability in the ENSO region and thus appear to occur independently of the model ENSO.

\section{APPENDIX C}

\section{The Contributions of Efficiency Factor and Transfer Factor}

Figure $5 \mathrm{c}$ shows the first term on the rhs of Eq. (3) (i.e., the ratios of the surface flux and transport variances). 
a) $e_{1} / e_{\mathbf{L}}$

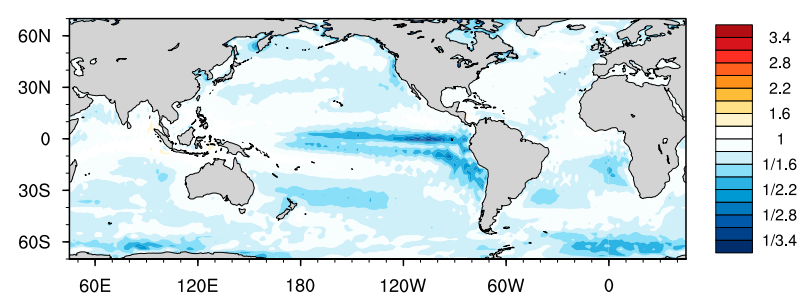

b) $G_{\mathrm{I}} / G_{\mathrm{L}}$

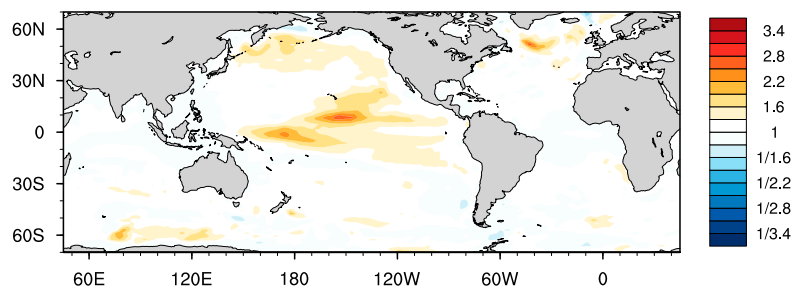

FIG. C1. As in Fig. 5c, but for (a) the ratio of the efficiency factors [the second term on the rhs of Eq. (3)] and (b) the ratio of the transfer factors [the third term on the rhs of Eq. (3)].

Here in Fig. C1 we show the contributions of the second and third terms on the rhs of Eq. (3). Figure C1a shows the ratios of the efficiency factors $e$ - which arise mainly from differences in the sum of the covariances between the heat flux terms. Figure C1b shows the ratios of the transfer factors $G$-which arise from differences in SST persistence as calculated from the lag-2 autocorrelation. The ratios in the efficiency factors are generally less than 1 , indicating the covariance terms are generally smaller in the interactive-cloud simulation than they are in the locked-cloud simulation. The ratios of the transfer factors are generally positive since SST persistence is slightly longer in the interactive simulation. Overall, the changes in the two factors are weak relative to the changes in the variances of the surface energy fluxes (Fig. 5c).

\section{REFERENCES}

Albern, N., A. Voigt, and J. G. Pinto, 2019: Cloud-radiative impact on the regional responses of the midlatitude jet streams and storm tracks to global warming. J. Adv. Model. Earth Syst., 11, 1940-1958, https://doi.org/10.1029/2018MS001592.

Alexander, M. A., 1992: Midlatitude atmosphere-ocean interaction during El Niño. Part I: The North Pacific Ocean. J. Climate, 5, 944-958, https://doi.org/10.1175/1520-0442(1992) 005<0944:MAIDEN>2.0.CO;2.

- I. Bladé, M. Newman, J. R. Lanzante, N.-C. Lau, and J. D. Scott, 2002: The atmospheric bridge: Influence of ENSO teleconnnections on air-sea interaction over the global oceans. J. Climate, 15, 2205-2231, https://doi.org/10.1175/1520-0442(2002) 015<2205:TABTIO >2.0.CO;2.

Bellenger, H., E. Guilyardi, J. Leloup, M. Lengaigne, and J. Vialard, 2014: ENSO representation in climate models: From CMIP3 to CMIP5. Climate Dyn., 42, 1999-2018, https://doi.org/10.1007/ s00382-013-1783-z.

Bony, S., and J.-L. Dufresne, 2005: Marine boundary layer clouds at the heart of tropical cloud feedback uncertainties in climate models. Geophys. Res. Lett., 33, L17810, https://doi.org/ 10.1029/2005GL023851.

Cayan, D. R., 1992: Latent and sensible heat flux anomalies over the northern oceans: Driving the sea temperature. J. Phys. Oceanogr., 22, 859-881, https://doi.org/10.1175/1520-0485(1992) 022<0859:LASHFA $>2.0$. CO 2 .

Ceppi, P., and D. L. Hartmann, 2015: Connections between clouds, radiation, and midlatitude dynamics: A review. Curr. Climate Change Rep., 1, 94-102, https://doi.org/10.1007/s40641-0150010-x.

$\longrightarrow$, and - 2016: Clouds and the atmospheric circulation response to warming. J. Climate, 29, 783-799, https://doi.org/ 10.1175/JCLI-D-15-0394.1.

—, Y.-T. Hwang, D. M. W. Frierson, and D. L. Hartmann, 2012: Southern Hemisphere jet latitude biases in CMIP5 models linked to shortwave cloud forcing. Geophys. Res. Lett., 39, L19708, https://doi.org/10.1029/2012GL053115.

— M. D. Zelinka, and D. L. Hartmann, 2014: The response of the Southern Hemispheric eddy-driven jet to future changes in shortwave radiation in CMIP5. Geophys. Res. Lett., 41, 32443250, https://doi.org/10.1002/2014GL060043.

Chen, Y., and A. D. D. Genio, 2009: Evaluation of tropical cloud regimes in observations and a general circulation mode. Climate Dyn., 32, 355-369, https://doi.org/10.1007/s00382-0080386-6.

Crueger, T., and B. Stevens, 2015: The effect of atmospheric radiative heating by clouds on the Madden-Julian oscillation. J. Adv. Model. Earth Syst., 7, 854-864, https://doi.org/10.1002/ 2015MS000434.

Davis, R. E., 1976: Predictability of sea surface temperature and sea level pressure anomalies over the North Pacific Ocean. J. Phys. Oceanogr., 6, 249-266, https://doi.org/10.1175/15200485(1976)006<0249:POSSTA $>2.0$.CO;2.

Eguchi, N., and M. Shiotani, 2004: Intraseasonal variations of water vapor and cirrus clouds in the tropical upper troposphere. J. Geophys. Res., 109, D12106, https://doi.org/10.1029/ 2003JD004314.

Eyring, V., S. Bony, G. A. Meehl, C. A. Senior, B. Stevens, R. J. Stouffer, and K. E. Taylor, 2016: Overview of the Coupled Model Intercomparison Project phase 6 (CMIP6) experimental design and organization. Geosci. Model Dev., 9, 19371958, https://doi.org/10.5194/gmd-9-1937-2016.

Fermepin, S., and S. Bony, 2014: Influence of low-cloud radiative effects on tropical circulation and precipitation. J. Adv. Model. Earth Syst., 6, 513-526, https://doi.org/10.1002/2013MS000288.

Fläschner, D., T. Mauritsen, B. Stevens, and S. Bony, 2018: The signature of shallow circulations, not cloud radiative effects, in the spatial distribution of tropical precipitation. J. Climate, $\mathbf{3 1}$, 9489-9505, https://doi.org/10.1175/JCLI-D-18-0230.1.

Grise, K. M., B. Medeiros, J. J. Benedict, and J. G. Olson, 2019: Investigating the influence of cloud radiative effects on the extratropical storm tracks. Geophys. Res. Lett., 46, 7700-7707, https://doi.org/10.1029/2019GL083542.

Harrop, B. E., and D. L. Hartmann, 2016: The role of cloud radiative heating in determining the location of the ITCZ in aquaplanet simulations. J. Climate, 29, 2741-2763, https:// doi.org/10.1175/JCLI-D-15-0521.1.

Jiang, X., D. E. Waliser, J.-L. Li, and C. Woods, 2011: Vertical cloud structures of the boreal summer intraseasonal variability 
based on CloudSat observations and ERA-interim reanalysis. Climate Dyn., 36, 2219-2232, https://doi.org/10.1007/S00382010-0853-8.

Langen, P. L., R. G. Graversen, and T. Mauritsen, 2012: Separation of contributions from radiative feedbacks to polar amplification on an aquaplanet. J. Climate, 25, 3010-3024, https:// doi.org/10.1175/JCLI-D-11-00246.1.

Lee, M.-I., I.-S. Kang, J.-K. Kim, and B. E. Mapes, 2001: Influence of cloud-radiation interaction on simulating tropical intraseasonal oscillation with an atmospheric general circulation model. J. Geophys. Res., 106, 14219-14233, https://doi.org/ 10.1029/2001JD900143.

Li, Y., and D. W. J. Thompson, 2016: Observed signatures of the barotropic and baroclinic annular modes in cloud vertical structure and cloud radiative effects. J. Climate, 29, 4723-4740, https://doi.org/10.1175/JCLI-D-15-0692.1.

- - _ - Y. Huang, and M. Zhang, 2014a: Observed linkages between the northern annular mode/North Atlantic Oscillation, cloud incidence, and cloud radiative forcing. Geophys. Res. Lett., 41, 1681-1688, https://doi.org/10.1002/ 2013GL059113.

,,-- G. L. Stephens, and S. Bony, 2014b: A global survey of the linkages between cloud vertical structure and large-scale climate. J. Geophys. Res. Atmos., 119, 3770-3792, https:// doi.org/10.1002/2013JD020669.

,-- , and S. Bony, 2015: The influence of atmospheric cloud radiative effects on the large-scale atmospheric circulation. J. Climate, 28, 7263-7278, https://doi.org/10.1175/JCLI-D-1400825.1.

- - , and Y. Huang, 2017: The influence of atmospheric cloud radiative effects on the large-scale stratospheric circulation. J. Climate, 30, 5621-5635, https://doi.org/10.1175/JCLID-16-0643.1.

— — - S. Bony, and T. M. Merlis, 2019: Thermodynamic control on the poleward shift of the extratropical jet in climate change simulations. J. Climate, 32, 917-934, https://doi.org/ 10.1175/JCLI-D-18-0417.1.

Lin, J.-L., D. Kim, M. Lee, and I. Kang, 2007: Effects of cloudradiative heating on Atmospheric General Circulation Model (AGCM) simulations of convectively coupled equatorial waves. J. Geophys. Res., 112, D24107, https://doi.org/10.1029/ 2006JD008291.

Lloyd, J., E. Guilyardi, and H. Weller, 2011: The role of atmosphere feedbacks during ENSO in the CMIP3 models. Part II: Using AMIP runs to understand the heat flux feedback mechanisms. Climate Dyn., 37, 1271-1292, https://doi.org/ 10.1007/s00382-010-0895-y.

,-- , and — 2012: The role of atmosphere feedbacks during ENSO in the CMIP3 models. Part III: The shortwave flux feedback. J. Climate, 25, 4275-4293, https://doi.org/10.1175/ JCLI-D-11-00178.1.

Ma, D., and Z. Kuang, 2011: Modulation of radiative heating by the Madden-Julian oscillation and convectively coupled Kelvin waves as observed by CloudSat. Geophys. Res. Lett., 38, L21813, https://doi.org/10.1029/2011GL049734.

Marshall, J., H. Johnson, and J. Goodman, 2001: A study of the interaction of the North Atlantic Oscillation with ocean circulation. J. Climate, 14, 1399-1421, https://doi.org/10.1175/ 1520-0442(2001)014<1399:ASOTIO > 2.0.CO;2.

Masunaga, H., M. Satoh, and H. Miura, 2008: A joint satellite and global cloud-resolving model analysis of a Madden-Julian oscillation event: Model diagnosis. J. Geophys. Res., 113, D17210, https://doi.org/10.1029/2008JD009986.
Mauritsen, T., and Coauthors, 2012: Tuning the climate of a global model. J. Adv. Model. Earth Syst., 4, M00A01, https://doi.org/ 10.1029/2012MS000154.

—, R. G. Graversen, D. Klocke, P. L. Langen, B. Stevens, and L. Tomassini, 2013: Climate feedback efficiency and synergy. Climate Dyn., 41, 2539-2554, https://doi.org/10.1007/s00382013-1808-7.

Middlemas, E. A., A. C. Clement, B. Medeiros, and B. Kirtman, 2019: Cloud radiative feedbacks and El Niño-Southern Oscillation. J. Climate, 32, 4661-4680, https://doi.org/10.1175/ JCLI-D-18-0842.1.

Miller, A. J., 1992: Large-scale ocean-atmosphere interactions in a simplified coupled model of the midlatitude wintertime circulation. J. Atmos. Sci., 49, 273-286, https://doi.org/10.1175/ 1520-0469(1992)049<0273:LSOAII > 2.0.CO;2.

Olonscheck, D., T. Mauritsen, and D. Notz, 2019: Arctic sea-ice variability is primarily driven by atmospheric temperature fluctuations. Nat. Geosci., 12, 430-434, https://doi.org/10.1038/ s41561-019-0363-1.

Rädel, G., T. Mauritsen, B. Stevens, D. Dommenget, D. Matei, K. Bellomo, and A. Clement, 2016: Amplification of El Niño by cloud longwave coupling to atmospheric circulation. Nat. Geosci., 9, 106-110, https://doi.org/10.1038/ngeo2630.

Riley, E. M., B. E. Mapes, and S. N. Tulich, 2011: Clouds associated with the Madden-Julian oscillation: A new perspective from CloudSat. J. Atmos. Sci., 68, 3032-3051, https://doi.org/10.1175/ JAS-D-11-030.1.

Schneider, E. K., B. P. Kirtman, and R. S. Lindzen, 1999: Tropospheric water vapor and climate sensitivity. J. Atmos. Sci., 56, 1649-1658, https://doi.org/10.1175/1520-0469(1999) 056<1649:TWVACS $>2.0$. CO; 2 .

Stephens, G., and Coauthors, 2002: The CloudSat mission and the A-Train: A new dimension of space-based observations of clouds and precipitation. Bull. Amer. Meteor. Soc., 83, 17711790, https://doi.org/10.1175/BAMS-83-12-1771.

Su, H., and J. H. Jiang, 2013: Tropical clouds and circulation changes during the 2006-07 and 2009-10 El Niños. J. Climate, 26, 399-413, https://doi.org/10.1175/JCLI-D-12-00152.1.

_ _ - J. Teixeira, A. Gettelman, X. Huang, G. Stephens, D. Vane, and V. S. Perun, 2011: Comparison of regimesorted tropical cloud profiles observed by CloudSat with GEOS5 analyses and two general circulation model simulations. J. Geophys. Res., 116, D09104, https://doi.org/10.1029/ 2010JD014971.

Tromeur, E., and W. B. Rossow, 2010: Interaction of tropical deep convection with the large-scale circulation in the MJO. J. Climate, 23, 1837-1853, https://doi.org/10.1175/2009JCLI3240.1.

Voigt, A., and T. A. Shaw, 2015: Circulation response to warming shaped by radiative changes of clouds and water vapour. Nat. Geosci., 8, 102-106, https://doi.org/10.1038/ngeo2345.

, and - 2016: Impact of regional atmospheric cloud radiative changes on shifts of the extratropical jet stream in response to global warming. J. Climate, 29, 8399-8421, https:// doi.org/10.1175/JCLI-D-16-0140.1.

- N. Albern, and G. Papavasileiou, 2019: The atmospheric pathway of the cloud-radiative impact on the circulation response to global warming: Important and uncertain. J. Climate, 32, 3051-3067, https://doi.org/10.1175/JCLI-D18-0810.1.

Wall, C. J., and D. L. Hartmann, 2015: On the influence of poleward jet shift on shortwave cloud feedback in global climate models. J. Adv. Model. Earth Syst., 7, 2044-2059, https:// doi.org/10.1002/2015MS000520. 
Watt-Meyer, O., and D. M. W. Frierson, 2017: Local and emote impacts of atmospheric cloud radiative effects onto the eddydriven jet. Geophys. Res. Lett., 44, 10 036-10044, https:// doi.org/10.1002/2017GL074901.

Xie, S.-P., 1999: A dynamic ocean-atmosphere model of the tropical Atlantic decadal variability. J. Climate, 12, 64-70, https://doi.org/10.1175/1520-0442-12.1.64.

$\mathrm{Yu}$, B., and G. J. Boer, 2006: The variance of sea surface temperature and projected changes with global warming. Climate Dyn., 26, 801-821, https://doi.org/10.1007/s00382006-0117-9.
Yuan, J., and R. A. Houze, 2013: Deep convective systems observed by A-Train in the tropical Indo-Pacific region affected by the MJO. J. Atmos. Sci., 70, 465-486, https://doi.org/ 10.1175/JAS-D-12-057.1.

Zhang, Y., S. Klein, G. G. Mace, and J. Boyl, 2007: Cluster analysis of tropical clouds using CloudSat data. Geophys. Res. Lett., 34, L12813, https://doi.org/10.1029/2007GL029336.

Zurovac-Jevtić, D., S. Bony, and K. Emanuel, 2006: On the role of clouds and moisture in tropical waves: A two-dimensional model study. J. Atmos. Sci., 63, 2140-2155, https://doi.org/ 10.1175/JAS3738.1. 